The Relevance of the Household Production Function and Its Implications for the Allocation of Time

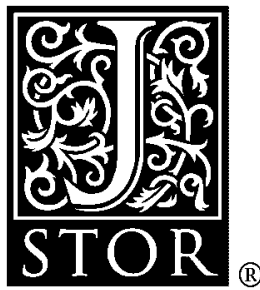

\author{
Robert A. Pollak; Michael L. Wachter \\ The Journal of Political Economy, Vol. 83, No. 2. (Apr., 1975), pp. 255-278.
}

Stable URL:

http://links.jstor.org/sici?sici=0022-3808\%28197504\%2983\%3A2\%3C255\%3ATROTHP\%3E2.0.CO\%3B2-E

The Journal of Political Economy is currently published by The University of Chicago Press.

Your use of the JSTOR archive indicates your acceptance of JSTOR's Terms and Conditions of Use, available at http://www.jstor.org/about/terms.html. JSTOR's Terms and Conditions of Use provides, in part, that unless you have obtained prior permission, you may not download an entire issue of a journal or multiple copies of articles, and you may use content in the JSTOR archive only for your personal, non-commercial use.

Please contact the publisher regarding any further use of this work. Publisher contact information may be obtained at http://www.jstor.org/journals/ucpress.html.

Each copy of any part of a JSTOR transmission must contain the same copyright notice that appears on the screen or printed page of such transmission.

The JSTOR Archive is a trusted digital repository providing for long-term preservation and access to leading academic journals and scholarly literature from around the world. The Archive is supported by libraries, scholarly societies, publishers, and foundations. It is an initiative of JSTOR, a not-for-profit organization with a mission to help the scholarly community take advantage of advances in technology. For more information regarding JSTOR, please contact support@jstor.org. 


\title{
The Relevance of the Household Production Function and Its Implications for the Allocation of Time
}

\section{Robert A. Pollak and Michael L. Wachter}

\author{
University of Pennsylvania
}

This paper provides a critique of the household production function approach and its application to the allocation of time. It is argued that many applications of the model, especially those making use of implicit "commodity prices," require that the household's technology exhibit constant returns and no joint production; otherwise, implicit commodity prices depend on the household's preferences as well as on its technology and the prices of market goods. Furthermore, joint production is pervasive in situations involving the allocation of time. In situations where household production theory does not provide a satisfactory framework for analysis, the paper suggests alternative approaches.

\section{Introduction}

Recent work by Becker, Lancaster, and others provides a new foundation for the theory of household behavior. According to the new view, the household purchases "goods" on the market and combines them with time in a "household production function" to produce "commodities." These commodities, rather than the goods, are the arguments of the household's utility function; market goods and time are not desired for their own sake, but only as inputs into the production of "commodities." 1

The authors are professor and associate professor of economics at the University of Pennsylvania. The research was supported by grants from the National Science Foundation and the National Institute of Child Health and Human Development. We wish to thank James J. Heckman, Michael Landsberger, John Muellbauer, Marc Nerlove, Stephen A. Ross, and the anonymous referees for helpful comments.

${ }_{1}^{1}$ The production function approach has been applied to a wide range of problems. Becker (1965) suggests that it be used to study such commodities as "seeing a play," which depends on the input of actors, script, theater, and the playgoer's time, and "sleeping," which depends on the input of a bed, house, and time. He has also used it (Becker 1960) to study fertility, introducing a commodity, the "quality of children," which is produced by inputs of goods and parental time. In Lancaster's model (1966a, $1966 b, 1971)$ goods possess "characteristics"; these characteristics, which we can identify with Becker's commodities, are the arguments of the household's utility function. Each unit of a good, for example, a "glass of orange juice," produces a vector of characteristics such as calories and vitamin C.

[Journal of Political Economy, 1975, vol. 83, no. 2]

(C) 1975 by The University of Chicago. All rights reserved. 
The new approach is oriented toward the study of nonmarket commodities and the associated allocation of household time-topics which have been neglected in the traditional theory of consumer behavior. Furthermore, stress is placed on the role of the household's technology as well as its tastes as a determinant of behavior. Typically, the analysis focuses on the demand for commodities as functions of "commodity prices," which, in turn, depend on goods prices and the household's technology.

In this paper we argue that, except in very special cases, the new theory does not provide a satisfactory model of the demand for commodities and the allocation of time as functions of "commodity prices." We identify the cases in which the new theory can do so, and propose alternative approaches for those in which it does not. We first analyze the conditions under which the household production function theory allows one to study nonmarket commodities as functions of commodity prices. We argue that this application of the household production function approach requires strong assumptions about the structure of the household's technology, in particular, constant returns to scale and the absence of joint production. If these assumptions are not satisfied, commodity prices depend on the household's consumption pattern. Hence, price differences among households reflect differences in tastes as well as technology. Since commodity prices are not determined solely by goods prices and technology, but also reflect the consumption pattern chosen by the household, it is misleading to treat the demand for commodities as a function of "commodity prices." Commodities which involve time as an input are a particular problem, since their production often involves joint production. Jointness is pervasive because time spent in many production activities is a direct source of utility as well as an input into a commodity. We suggest that the household production function model, with its concentration on commodity prices, provides a satisfactory account of the allocation of time only for households which are indifferent among alternative uses of their time. When joint production and/or nonconstant returns to scale are present, we propose that commodity prices be avoided and that the demand for commodities be viewed as a function of goods prices, the wage rate, and nonlabor income.

An additional problem occurs when the household production function model is applied to variables which may be interpreted as "utilities" (numbers representing preference orderings) rather than "commodities" (the outputs of production processes). In cases of this type, the production function approach loses its unique identity and cannot be distinguished from a variety of hypotheses about the structure of the household's preferences. Activities which generate "utilities" can be studied, but the analysis must focus on the household's allocation of goods and time among these activities rather than their "output." The resulting analytical framework is closer to traditional demand theory than to the household production function model. 
We proceed as follows: in Section 2 the basic household production function model is presented and its implications for the demand for goods and the demand for commodities are examined. Our discussion in Section 2 assumes that the household's technology exhibits constant returns to scale and no joint production. The consequences of relaxing these assumptions are discussed in Section 3. In Section 4 we consider the role of time in the household production function. In Section 5 alternative approaches to studying nonmarket activities and the allocation of time are suggested.

\section{Household Production Functions}

Suppose that there are $n$ goods, denoted by $X=\left(x_{1}, \ldots, x_{n}\right)$, and $m$ commodities, denoted by $Z=\left(z_{1}, \ldots, z_{m}\right)$. The goods are inputs into the production of commodities. We ignore until Section 4 the presence of household time as an input along with market goods. In this section we assume that each commodity is produced by a separate constant-returns-to-scale production function. This assumption rules out joint production and enables us to identify the inputs used to produce each commodity. Let $y_{r i}$ denote the quantity of the $i$ th good used as an input in the production of the $r$ th commodity, and let $Y_{r}$ denote the corresponding vector: $Y_{r}=\left(y_{r 1}, \ldots, y_{r n}\right) .^{2}$ Denote the production function for the $r$ th commodity by $f^{r}: z_{r}=f^{r}\left(Y_{r}\right)=f^{r}\left(y_{r 1}, \ldots, y_{r n}\right)$. Constant returns to scale implies $f^{r}\left(\lambda Y_{r}\right)=\lambda f^{r}\left(Y_{r}\right)$. Since every good need not be used in the production of every commodity, some of the $y_{r i}$ 's may be zero. The goods vector $X$ is related to the input vectors by

$$
X=\sum_{s=1}^{m} Y_{s}
$$

In the household production function model, the household's preferences are represented by a utility function $U(Z)$ defined over the commodity space. Goods are not desired for their own sake, but only because they are inputs for the production of commodities. In the household production function model the household faces two types of constraints on its consumption opportunities: the budget constraint and the limitation imposed by its technology. Hence, the demand for goods and the demand for commodities both depend on goods prices, the household's income, its tastes, and its technology.

We define the cost function $C(P, Z)$ as the cost of the least expensive collection of goods capable of producing the commodity vector $Z$ when

\footnotetext{
${ }^{2}$ Although Becker often uses fixed-coefficient production functions as an expositional device, we shall not, since fixed coefficients are not an integral part of the household production function model.
} 
goods prices are $P$. Formally

$$
C(P, Z)=\min \sum_{k=1}^{n} p_{k} x_{k}
$$

subject to $(X, Z) \in \Omega$, where $\Omega$ is the "production set" whose elements are technically feasible input-output vectors. We hereafter denote the feasible set of commodity vectors producible from the goods vector $X$ by $S(X)$.

In the household production function model primary stress is placed on the demand functions for commodities rather than the demand functions for goods. Following this literature, we define implicit commodity prices $\left(\pi_{1}, \ldots, \pi_{m}\right)=\pi$ as the marginal costs of producing commodities:

$$
\pi_{r}(P, Z)=\frac{\partial C(P, Z)}{\partial Z_{r}} .
$$

Under certain conditions these implicit commodity prices are independent of the $z$ 's, so $\pi_{r}(P, Z)=\pi_{r}(P) .{ }^{3}$ When they are, the budget constraint in the commodity space can be written as

$$
\sum_{s=1}^{m} \pi_{s}(P) z_{s}=\mu .
$$

Maximizing $U(Z)$ subject to this budget constraint yields commodity demand functions $Z_{r}=g^{r}(\pi, \mu)$, or, in vector form $Z=g(\pi, \mu)$. These demand functions exhibit all of the properties of traditional demand theory; they are homogeneous of degree zero in $(\pi, \mu)$ and satisfy the budget constraint and the Slutsky sign and symmetry conditions. Since the household production function model places no special restrictions on the utility function $U(Z)$, it implies no additional restrictions on the commodity demand functions.

If we are to preserve the formal analogy with traditional demand theory, it is crucial that the commodity prices be independent of the commodity bundle which the household chooses. The advantage of preserving this formal correspondence is that by doing so we have access to the body of established theoretical results of traditional demand theory. If implicit commodity prices depend on the commodity bundle consumed, then the commodity demand relations correspond to those in a model in which consumers are monopsonists or are offered tie-in sales, and there are virtually no substantive results for these cases. In Section 3, we discuss the case in which commodity prices violate this condition and depend on the $z$ 's. We now identify a case in which commodity prices are independent of the commodity bundle consumed.

\footnotetext{
${ }^{3}$ Much of this section and the next is devoted to investigating the conditions under
} which implicit commodity prices are independent of the $Z$ 's. 
Theorem: If the household's technology exhibits constant returns to scale and no joint production, then the budget constraint in the commodity space is of the form

$$
\sum_{s=1}^{m} \pi_{s} z_{s}=\mu
$$

where the $\pi$ 's depend on goods prices and the household's technology, but not on the commodity bundle consumed.

Proof: With no joint production, we can write the cost function $C(P, Z)$ as

$$
C(P, Z)=\sum_{s=1}^{m} C^{s}\left(P, z_{s}\right),
$$

where $C^{r}\left(P, z_{r}\right)$ is the cost function associated with the production function $z_{r}=f^{r}\left(Y_{r}\right)$. Constant returns to scale implies

$$
C^{r}\left(P, z_{r}\right)=C^{r}(P, 1) z_{r}
$$

Hence the cost function becomes

$$
C(P, Z)=\sum_{s=1}^{m} C^{s}(P, 1) z_{s}
$$

and

$$
\pi_{r}=C^{r}(P, 1)
$$

The $\pi$ 's reflect both the goods prices which the household faces and the household's technology, but they are independent of the household's tastes. They represent the marginal cost of each commodity to the household, and, under our assumptions of constant returns to scale and no joint production, they are independent of the quantity of the commodity in question as well as the quantities of all other commodities consumed by the household.

Although the household production function literature places primary stress on the demand for commodities, the implications of the model for the demand for goods also must be developed. To find the demand functions for goods, the most direct approach is to determine the utility function for goods implied by the household's technology and its utility function for commodities and then to maximize this goods utility function subject to the appropriate budget constraint. We begin by constructing the utility function for goods, $V(X)$. The household's technology allows us to associate a set of feasible commodity vectors, $S(X)$, with every goods vector $X$. Commodity vectors in $S(X)$ are producible from the input vector $X$; those not in $S(X)$ are not producible. The utility function, $U(Z)$, is used to select a best commodity vector $Z^{*}$ from this feasible set. Hence, one can define the utility function over the goods space, $V(X)$, by associating with the goods vector $X$ the utilitv of the commodity 
vector $Z^{*}$; that is, $V(X)=\max U(Z)$ subject to $Z \in S(X) .{ }^{4}$ Finally, to find the goods demand functions, maximize $V(X)$ subject to the budget constraint

$$
\sum_{k=1}^{n} p_{k} x_{k}=\mu
$$

where $\mu$ denotes total expenditure or "income." This yields the "goods demand functions," $x_{i}=h^{i}(P, \mu)$, or, in vector form, $X=h(P, \mu)$, where $P$ is the vector of goods prices. That is, the household's technology and its utility function over the commodity space imply a utility function over the good space; maximizing that utility function subject to the budget constraint yields demand functions for goods. It should be emphasized that $V(X)$, the translation of the utility function into the goods space, reflects both tastes and technology. Traditional demand theory treats $V(X)$ as the household's utility function and is thus guilty of confounding tastes and technology, rather than maintaining a separation between them. A consequence of this, as the household production function literature points out, is that changes in demand which are clearly attributable to changes in technology must formally be described as changes in tastes.

The household production function model emphasizes several key points which are overlooked in the traditional theory of the household. First, it develops a framework for analyzing the allocation of goods (and time) within the household. Second, it stresses the role of the household's technology as well as its tastes as a determinant of behavior. This opens the possibility of attributing variations in household behavior to changes in technology as well as to changes in goods prices or income operating through the budget constraint or to changes in tastes. Third, the household production function model focuses our attention on the outputs of the household technology, the commodities, while the traditional theory ignores commodities and considers only market goods.

From the standpoint of the household, the budget constraint and the technological constraints are coequal limitations of its consumption possibilities. But from the standpoint of the economist investigating household behavior, there is a crucial difference between them: the household's budget constraint is directly observable, while the household's technology must be inferred from its behavior. To construct commodity prices which can be utilized as arguments of these demand functions, the

\footnotetext{
${ }^{4}$ Mild regularity conditions on the production functions, together with the assumption of constant returns to scale, imply that the production set $\Omega$ is convex. If the production set $\Omega$ is convex and the commodity utility function $U(Z)$ is quasi-concave, then the implied goods utility function $V(Z)$ is quasi-concave. The proof is straightforward. Notice that the convexity assumption applies to the production set $\Omega$ and that its convexity implies the convexity of $S(X)$.
} 
parameters of the technology must be known. A procedure for implementing the household production function model involves two stages. The first stage includes estimation of the household's technology and construction of commodity prices from goods prices using the estimated parameters of the technology. These commodity prices serve as arguments of the commodity demand functions, $Z=g(\pi, \mu)$; the estimation of these commodity demand functions constitutes the second stage.

There are three approaches to investigating the household's technology. One is direct estimation of the production functions using data on imputs of goods and outputs of commodities. The second is the calculation of the total or unit cost functions; these yield estimates of commodity prices at various configurations of goods prices. The third is to estimate the "constant output factor demand functions," which show the demand for goods as a function of goods prices and commodity outputs. Since these demand functions are the partial derivatives of the cost functions with respect to goods prices, and since the cost functions are homogeneous of degree 1 in goods prices, the cost functions can be constructed from them by Euler's theorem.

Once commodity prices have been calculated, the household production function approach can use them as independent variables in the analysis of the demand for commodities. Because the commodity prices depend on the household's technology as well as on goods prices, they can be used to express the fundamental insight of the household production function model, namely, that the household is constrained by technology as well as by its limited budget, and that changes in technology provide a possible explanation of changes in household behavior.

\section{Complications}

In this section we consider the consequences of joint production and nonconstant returns to scale for the household production function model. We show that either one implies that commodity prices depend on the commodity bundle consumed and argue that this impares the analytical usefulness of commodity prices as a tool for analyzing the demand for commodities.

Assume that the household's technology can be represented by a generalized production function $z_{1}=T\left(z_{2}, \ldots, z_{m}, x_{1}, \ldots, x_{n}\right)$. Unless explicitly stated to the contrary, constant returns to scale and/or the absence of joint production are not assumed.

Even with joint production and nonconstant returns to scale, there is no difficulty with the demand functions for goods. To find them, we define the implied goods utility function, $V(X)$, by $V(X)=\max U(Z)$ subject to $z_{1}=T\left(z_{2}, \ldots, z_{m}, x_{1}, \ldots, x_{n}\right)$. Maximizing $V(X)$ subject to the budget constraint $\sum p_{k} x_{k}=\mu$ yields the goods demand functions 
$X=h(P, \mu)$. If the utility function $V(X)$ is quasi-concave, these demand functions exhibit all the properties of demand functions of traditional demand theory, and joint production and nonconstant returns to scale have no impact on the general properties of the goods demand functions. But the quasi-concavity of $V(X)$ does not follow from our assumptions about $U(Z)$ unless we place further restrictions on the technology. ${ }^{5}$

To determine the commodity demand functions, we translate the budget constraint from the goods space into the commodity space. The cost function $C(P, Z)$ is defined as the minimum cost of producing the commodity bundle $Z$ at goods prices $P$; that is, $C(P, Z)=\min \sum p_{k} x_{k}$, subject to $z_{1}=T\left(z_{2}, \ldots, z_{m}, x_{1}, \ldots, x_{n}\right)$. The household maximizes $U(Z)$ subject to the translated budget constraint $C(P, Z)=\mu$. The first-order conditions imply

$$
\frac{\partial U(Z)}{\partial z_{r}}=\lambda \frac{\partial C(P, Z)}{\partial z_{r}} \quad r=1, \ldots, m,
$$

and we again interpret the partial derivatives of the cost function as implicit commodity prices; that is, the marginal cost of each commodity is its implicit or shadow price. Except in special cases, these implicit prices depend on the household's technology, the goods prices, and the commodity bundle consumed by the household.

We define the "implicit income" of the household consuming the commodity bundle $Z$ at goods prices, $P, I(P, Z)$, by

$$
I(P, Z)=\sum_{s=1}^{m} z_{s} \frac{\partial C(P, Z)}{\partial z_{s}}
$$

That is, $I(P, Z)$ is the cost of the commodity bundle $Z$ evaluated at the implicit commodity prices. If the household's technology exhibits constant returns to scale, then $C(P, Z)=\mu$ implies $I(P, Z)=\mu$ by Euler's theorem. Without constant returns, $I(P, Z) \neq \mu$; the discrepancy depends on the relative importance of increasing and decreasing returns.

When commodity prices depend on the commodity bundle consumed, we do not believe that it is analytically useful to view the demand for commodities as a function of commodity prices and implicit income. Since the $\pi$ 's and $I$ depend on the commodity bundle consumed, they cannot be treated as predetermined parameters from the standpoint of the household. In Section 2 we showed that the implicit commodity prices are independent of the commodity bundle consumed if the house-

\footnotetext{
${ }^{5}$ The problem is with increasing returns rather than joint production. If the production set $\Omega$ is convex, it is easy to show that the quasi-concavity of $U(Z)$ implies the quasiconcavity of $V(X)$. With increasing returns, however, the production set is not convex, and it may be so nonconvex as to yield a goods utility function which is not quasi-concave. For example, suppose $U\left(z_{1}, z_{2}\right)=z_{1}^{1 / 2}+z_{2}^{1 / 2}$ and the household's technology is given by the production functions $z_{1}=x_{1}^{4}$ and $z_{2}=x_{2}^{4}$. The implied goods utility function is $V\left(x_{1}, x_{2}\right)=x_{1}^{2}+x_{2}^{2}$, which is clearly not quasi-concave.
} 
hold's technology exhibits both constant returns to scale and no joint production. We now show the converse: in the absence of fixed costs, this is the only case in which implicit commodity prices are independent of the $z$ 's.

Theorem: Suppose the household's technology is continuous, and $T(0, \ldots, 0,0, \ldots, 0)=0$. Then implicit commodity prices are independent of the commodity bundle consumed only if the household's technology exhibits both constant returns to scale and no joint production. ${ }^{6}$

Proof: If implicit commodity prices are independent of the commodity bundle consumed, then the cost function can be written as

$$
C(P, Z)=C^{o}(P)+\sum_{s=1}^{n} C^{s}(P) z_{s}
$$

Since the technology is continuous and $T(0, \ldots, 0,0, \ldots, 0)=0$, $C(P, 0)=0$, and, hence, $C^{o}(P)=0$. To complete the proof, one must show that $C^{r}(P)$ is a unit cost function corresponding to some constantreturns-to-scale production function. A formal proof can be found in Diewert (1972) and Hall (1973). Q.E.D.

Thus far we have focused on the conditions under which absolute commodity prices, $\pi_{r}=[\partial C(P, Z)] / \partial z_{r}$, are independent of the commodity bundle consumed. It is possible, however, for relative commodity prices $\left(\partial C / \partial z_{\mathbf{r}}\right) /\left(\partial C / \partial z_{s}\right)$ to be independent of the commodity bundle consumed, even when absolute commodity prices are not. ${ }^{7}$ An example of a case in which relative commodity prices are independent of the $z$ 's but absolute prices are not is given by the technology

$$
\left(\sum_{s=1}^{m} a_{s} z_{s}\right)^{2}=\phi(X)
$$

where $\phi(X)$ is a Cobb-Douglas production function. This technology does not exhibit constant returns to scale, since doubling the $x$ 's does not permit a doubling of the $z$ 's. With constant returns to scale, however, relative commodity prices are independent of the $z$ 's if and only if absolute commodity prices are independent of the $z$ 's. In the light of the above theorem, this assertion is equivalent to the following:

Theorem: Suppose the household's technology exhibits constant returns to scale. Relative commodity prices are independent of the commodity bundle consumed by the household if and only if the household's technology exhibits no joint production.

\footnotetext{
6 Muellbauer (1973) proves this result and discusses its implications for using the household production function model as a foundation for a theory of hedonic price indexes.

7 This was pointed out to us by John Muellbauer and Stephen A. Ross.
} 
Proof: The "if" assertion is trivial. To establish "only if," suppose that relative prices are independent of $Z$. Then the locus of $z$ 's satisfying the feasibility constraint implied by $(P, \mu)$ is given by

$$
z_{1}=\alpha^{0}(P, \mu)-\sum_{s=2}^{m} \alpha^{s}(P, \mu) z_{s} .
$$

By constant returns to scale, if the commodity vector $Z$ is feasible at $(P, \mu)$, then $\lambda Z$ is feasible at $(P, \lambda \mu)$. Hence

$$
\lambda z_{1}=\alpha^{0}(P, \lambda \mu)-\sum_{s=2}^{m} \alpha^{s}(P, \lambda \mu) \lambda z_{s}
$$

for all $\lambda>0$. Setting $\lambda=1 / \mu$ and solving for $\mu$ yields

$$
\mu=\frac{z_{1}}{\alpha^{0}(P, 1)}+\sum_{s=2}^{m} \frac{\alpha^{s}(P, 1)}{\alpha^{0}(P, 1)} z_{s} .
$$

Hence, the cost function is of the form

$$
C(P, Z)=\sum_{s=1}^{m} C^{s}(P) z_{s}
$$

and the household's technology exhibits no joint production. Q.E.D.

For the remainder of this section, we shall assume that the household's technology exhibits constant returns to scale. We have already seen that it is possible to combine the two types of constraints facing the householdthe market constraint represented by the budget line and the technological constraint represented by the household production function-into the single constraint. To do this, we focus on the feasible set in the commodity space determined by goods prices, the household's technology, and its income. In the traditional theory of the household which does not recognize commodities, the boundary of the feasible set in the goods space is a hyperplane whose slope reflects the ratio of goods prices. In the household production function model with no joint production, the boundary of the feasible set in the commodity space is a hyperplane whose slope reflects both goods prices and the household's technology. As long as the boundary of the feasible set is a hyperplane, the slope corresponding to one commodity bundle on the frontier is the same as that corresponding to any other efficient bundle.

Consequently, these slopes or implicit commodity prices not only reflect the constraints facing the household but also code all of the relevant information about these constraints; no further information about technology or goods prices is needed to define the feasible set. Confronting this feasible set with preferences, the household chooses the best attainable commodity bundle. Since commodity prices are inde- 
pendent of the commodity bundle consumed, we can view the household as adjusting its consumption so as to bring marginal rates of substitution into alignment with the commodity price ratios determined by goods prices and technology.

With joint production (and constant or nonconstant returns to scale) the boundary of the feasible set is no longer a hyperplane. Hence, one must be very cautious in focusing attention on the slope of the boundary of the feasible set at the optimal point, since, in this case, the slope does not code all the relevant information about the constraint faced by the household. Specifically, commodity prices reflect the household's preferences as well as goods prices, income, and the household's technology. Although commodity price ratios are equated to marginal rates of substitution in equilibrium, the adjustment process takes place on both sides; as the commodity bundle changes, so do both commodity prices and marginal rates of substitution.

To illustrate the difficulties caused by the dependence of commodity prices on the commodity bundle consumed, consider two households with identical technologies who face the same goods prices and have equal incomes. These two households have the same cost function and the same feasible set in the commodity space. If the technology exhibits joint production, then the frontier of the feasible set is nonlinear and commodity prices vary with the commodity bundle chosen. Households with different tastes will select different commodity bundles, and, since the frontier is nonlinear, the commodity bundles they select will imply different commodity prices. The unwary economist might attribute some part of the difference in the consumption patterns of our two households to these differences in commodity prices, but such an interpretation would be highly misleading; the differences in commodity prices are a reflection of differences in tastes, not of differences in opportunities.

The dependence of commodity prices on the commodity bundle consumed makes it impossible to utilize the two-stage process outlined in Section 1. Although the estimation of the household's technology is complicated by joint production, it is still possible. However, the analysis of the demand for commodities in terms of maximizing a utility function subject to a linear budget constraint is no longer appropriate; commodity prices depend on the commodity bundle consumed and, hence, on the household's tastes.

If commodity prices are not analytically useful for studying the demand for commodities when the household's technologies exhibit joint production, where does this leave the household production function model? There are two alternatives. First, one can restrict the application of the model to those cases in which the technology exhibits no joint production. Although no one can object in principle to restricting the model to those cases, the usefulness of the restricted model depends on the prevalence of 
joint production. In Section 4 we argue that joint production is pervasive when the role of time in the household production process is recognized; this implies that restricting the application of the model in this way is very undesirable. Second, one can argue that commodity prices are not central to the household production function approach. Without commodity prices, we can derive commodity demand functions which depend on goods prices and income. These demand functions are of substantial interest even in the no-joint-production case, since we are often interested in the effects of goods prices on the consumption of commodities; but they must assume a primary role when commodity prices depend on the commodity bundle consumed.

\section{The Role of Time}

The allocation of time has played a central role in most applications of the household production function model. In Becker's exposition, the household purchases goods and combines them with time in a household production function to produce commodities. These commodities, rather than the goods or time, are the sources of utility. ${ }^{8}$

In Section $4 A$ we introduce time into the basic model with constant returns to scale and no joint production. We assume that the household can sell "time" or "labor" on the market, and that it can do so at a single wage rate which is beyond its control and independent of the commodity bundle which it consumes. ${ }^{9}$ Section $4 B$ extends the model to include joint production and nonconstant returns to scale. We argue that when time is an input in the household production process, joint production is the rule and not an exception because the input of time into many household activities is itself a direct source of utility or disutility to members of the household engaged in the activity. This is a type of joint production, and, like any form of joint production, it implies that prices are not independent of the commodity bundle consumed.

\section{A. Time in the Basic Model}

The traditional theory deals with the labor-leisure choice by treating leisure as an argument of the utility function; we denote the utility function by $V\left(X, T_{c}\right)$, where $T_{c}$ denotes "leisure," or, more precisely,

\footnotetext{
8 The notion of commodity prices involving the wage rate are anticipated in the work of Mincer (1962, 1963). Although Mincer focuses on goods and leisure (or work) rather than commodities, he writes the price of a good as the sum of a direct component related to the market price of the good and an indirect component related to the opportunity cost of time.

${ }^{9}$ In Becker's model (1965) there are many wage rates, and they depend on the commodity bundle the household consumes; also see Diewert (1971) for further work in this direction. We ignore these complications to focus on others.
} 
time not spent at work. In the Becker terminology, $T_{c}$ represents "time spent at consumption." 10 The demand functions are found by maximizing $V\left(X, T_{\mathrm{c}}\right)$ subject to two interrelated constraints, one for goods,

and the other for time,

$$
\sum_{k=1}^{n} p_{k} x_{k}=A+w T_{L}
$$

$$
T_{\mathrm{c}}+T_{L}=T \text {, }
$$

where $A$ is nonlabor income, $w$ the fixed wage rate, $T_{L}$ working time, and $T$ total time available-for example, 24 hours, if the period is 1 day and the household consists of one person. Collapsing these two constraints into a single resource constraint by solving for $T_{L}$ yields

$$
\sum_{k=1}^{n} p_{k} x_{k}+w T_{c}=A+w T=S^{\prime},
$$

where $S^{\prime}$ is "full income." 11

Maximizing $V\left(X, T_{c}\right)$ subject to this constraint yields demand functions for goods and a demand function for "leisure":

$$
\begin{aligned}
x_{i} & =h^{i}(P, w, A) \\
T_{c} & =h^{T c}(P, w, A) .
\end{aligned}
$$

These demand functions for goods and leisure are homogeneous of degree 0 in $(P, w, A)$ and satisfy the budget constraint and the appropriate versions of the Slutsky sign and symmetry conditions. If we wish to emphasize the role of full income, we can write the demand functions as

$$
\begin{aligned}
x_{i} & =\hat{h}^{i}\left(P, w, S^{\prime}\right) \\
T_{c} & =\hat{h}^{T c}\left(P, w, S^{\prime}\right) .
\end{aligned}
$$

The traditional theory is often presented in a form which ignores the labor-leisure choice and focuses on the allocation of expenditure among goods. ${ }^{12}$ This form of the traditional theory is a special case of the full traditional model which arises when goods are separable from leisure in the household's utility function:

$$
V\left(X, T_{c}\right)=W\left[\bar{V}(X), T_{c}\right] .
$$

In the separable case, the allocation of total expenditure is independent of the wage rate. That is, the demand functions for goods are of the form

$$
x_{i}=h^{i}(P, \mu),
$$

\footnotetext{
10 Following Becker, we do not distinguish between "time spent at consumption" and "time spent at household production."

${ }^{11}$ Following Becker's usage, when there is a single wage rate independent of the commodity bundle consumed, we define full income to be $A+w T$.

12 This issue is discussed by Mincer (1963).
} 
where $\mu$ denotes total expenditure on goods. Total expenditure on goods is a function of all goods prices, nonlabor income, and the wage rate; but the wage rate and nonlabor income influence the demand for goods only through their influence on total expenditure. Thus, offsetting changes in the wage rate and nonlabor income which leave total expenditure on goods unchanged will not change the goods consumption pattern.

To incorporate time into the household production function model, we let $t_{r}$ denote time devoted to the production of commodity $r$ and $z_{r}=f^{r}\left(Y_{r}, t_{r}\right)$ denote the production function for commodity $r$. To find the commodity demand functions when the household's technology exhibits constant returns to scale and no joint production, we define commodity prices $\pi=\left(\pi_{1}, \ldots, \pi_{m}\right)$ to be the implicit or shadow prices implied by the technology. With constant returns to scale and no joint production, the price of each commodity is equal to its unit cost function

$$
\pi_{r}=C^{r}(P, w, 1) .
$$

These commodity prices are independent of the commodity bundle consumed, and we can write the budget constraint in the commodity space as

$$
\sum_{s=1}^{m} \pi_{s} z_{s}=A+w T=S^{\prime} .
$$

Maximizing the utility function $U(Z)$ subject to this constraint yields the commodity demand functions

$$
z_{i}=g^{i}(\pi, w, A)
$$

or, following Becker and emphasizing the role of full income,

$$
z_{i}=\hat{g}^{i}\left(\pi, S^{\prime}\right) \text {. }
$$

To find the demand functions for goods implied by the household production function model, we translate the utility function $U(Z)$ into the goods space. With each vector $\left(X, T_{c}\right)$ is associated a feasible set of commodity vectors which we denote by $S\left(X, T_{c}\right)$. We define a utility function in the $\left(X, T_{c}\right)$ space, $V\left(X, T_{c}\right)$, by

$$
V\left(X, T_{c}\right)=\max U(Z)
$$

subject to $z \in S\left(X, T_{c}\right) \cdot{ }^{13}$ Maximizing $V\left(X, T_{c}\right)$ subject to the resource constraint yields demand functions

$$
\begin{aligned}
x_{i} & =h^{i}(P, w, A) \\
T_{c} & =h^{T c}(P, w, A) .
\end{aligned}
$$

${ }^{13}$ Since the production set $\Omega$ is convex, the quasi-concavity of $U(Z)$ implies the quasi-concavity of $V\left(X, T_{c}\right)$. 
These demand functions for goods and leisure have all the familiar properties of demand functions for goods and leisure; they are homogeneous of degree zero in $(P, w, A)$, they satisfy the budget constraint, and they satisfy appropriate versions of the Slutsky sign and symmetry conditions. ${ }^{14}$

\section{B. Complications}

We saw in Section 3 that joint production and nonconstant returns to scale substantially complicate the commodity demand functions but not the goods demand functions. The same results hold when time is included in the model. The analysis of the goods demand functions earlier in this section made no use of the assumptions of constant returns to scale or no joint production and hence requires no modification when these assumptions are dropped. ${ }^{15}$ The derivation of the commodity demand functions, however, did make use of these assumptions. Without them, the boundary of the feasible set in the commodity space is given by the cost function $C(P, w, Z)=\mu$, where

$$
C(P, w, Z)=\min \sum_{k=1}^{n} p_{k} x_{k}+w T_{c}
$$

subject to the technological constraint $Z \in S\left(X, T_{c}\right)$. Corresponding to each commodity bundle we define implicit or shadow commodity prices as the partial derivatives of the cost function

$$
\pi_{r}(P, w, Z)=\frac{\partial C(P, w, Z)}{\partial z_{r}}
$$

and implicit income by

$$
I(P, w, Z)=\sum_{s=1}^{m} \pi_{s}(P, w, Z) z_{s}
$$

Unless the technology exhibits constant returns to scale and no joint production, implicit commodity prices depend on the commodity bundle consumed; without constant returns to scale, so does implicit income. ${ }^{16}$

\footnotetext{
14 As Becker (1965) has emphasized, this formulation is symmetrical in its treatment of goods and time costs of commodities, placing the indirect or time costs on the same footing as the direct or goods costs. The role of the wage rate, however, appears to be more complex than those of goods prices because it enters both the cost function $C(P, w, Z)$ and the resource constraint $A+w T$, since the wage rate is both a "goods price" and a determinant of "full income." Actually, the symmetric treatment of goods and time can be completed by considering a household which has an initial endowment of goods as well as time. This yields a constraint which treats goods and time symmetrically on the income side as well as the cost side and emphasizes the formal similarity between endowments of goods and endowments of time.

15 This is not quite true. A quasi-concave utility function in the goods-time space is compatible with only limited increasing returns to scale.

${ }^{16}$ In some studies, $I$ rather than $S^{\prime}$ is defined as "full income"; see, for example, Willis (1973).
} 
As in Section 3, we do not believe that commodity demand functions whose arguments are commodity prices which change with the commodity bundle chosen are useful analytical constructs. These "demand functions" correspond to consumer behavior under monopsony or tie-in sales, but not to the traditional theory of the household as a price taker. Consequently, the relevancy of the household production function approach to the allocation of time depends crucially on the assumptions of constant returns to scale and no joint production. Under quite general conditions, however, these assumptions are likely to be violated.

The major problem in studying the allocation of time in the household production function model centers on joint production rather than nonconstant returns to scale. Casual empiricism suggests to us that many household production processes exhibit increasing or decreasing returns to scale in ways which are directly related to the use of time. Examples related to set-up time, time spent assembling materials, etc., are easy to find but depend on the particular commodity or production process being considered. Hence, it is difficult to make a general argument concerning the importance of nonconstant returns. ${ }^{17}$ With joint production, however, it is possible to make a general argument. The point is best approached through an example.

Consider a model with two household production processes. For definiteness, suppose the first produces a "home cooked meal" and the second a "clean house." Each of these processes requires inputs of both purchased goods and time. The time used in these activities can be that either of household members or of others hired to engage in these activities. There is no need to modify the model to include the services of hired outsiders; they are already included among the goods and their price is the relevant wage rate. To simplify the discussion, suppose the household has only one member. Formally, we can use the household production function model to represent the situation just described. There are two commodities, $z_{1}$ and $z_{2}$, which enter the household's utility function, $U\left(z_{1}, z_{2}\right)$. Each is produced by a separate production process. These processes combine market goods, including the services of hired workers, with household time to produce the commodities $z_{1}+f^{1}\left(Y_{1}, t_{1}\right)$ and $z_{2}=f^{2}\left(Y_{2}, t_{2}\right)$.

There is no joint production in this model, so there is no difficulty treating the demand for commodities as functions of commodity prices; however, we do not believe that the formal model is a plausible representation of the situation we have described. In particular, we object

\footnotetext{
17 Muth (1966) argues that constant returns to scale are a tautological property of any production process. Even if one accepts this as a metaphysical proposition, it has no relevancy here; what we require is constant returns to scale in $\left(Y_{r}, t_{r}\right)$, the inputs which the household can purchase on the market, not constant returns to scale in some augmented set of inputs.
} 
to the implied but crucial assumption that time spent cooking and time spent cleaning are "neutral" from the standpoint of the household and that only the "outputs" of these production processes enter the household's utility function. A more plausible assumption is that the household is not indifferent among all situations which involve the same output of home cooked meals and clean houses but involve different amounts of hired labor and household labor. Instead, we suggest that household time spent cooking or cleaning is a direct source of utility or disutility to the household. Consequently, household decisions about the allocation of time reflect not only production considerations but also direct household preferences as to the uses of time.

Formally, the situation can be treated in the household production function framework, but since household time spent cooking and cleaning is a source of utility, there are now four commodities instead of two. The household's utility function is then $U\left(z_{1}, z_{2}, z_{3}, z_{4}\right)$. We still have two production processes or activities which combine goods (including the services of nonmembers of the household) and household time to produce commodities, but these processes now involve joint production;

and

$$
\begin{aligned}
& z_{1}=F^{1}\left(Y_{1}, t_{1}\right) \\
& z_{3}=t_{1}
\end{aligned}
$$

$$
\begin{aligned}
& z_{2}=F^{2}\left(Y_{2}, t_{2}\right) \\
& z_{4}=t_{2} .
\end{aligned}
$$

The commodities $z_{3}$ and $z_{4}$ reflect the household time spent in the production activities associated with $z_{1}$ and $z_{2}$, respectively.

With joint production of the type we have specified, the cost function $C(P, w, Z)$ assumes the form

$$
C(P, w, Z)=C^{1}\left(P, w, z_{1}, z_{3}\right)+C^{2}\left(P, w, z_{2}, z_{4}\right),
$$

where the superscripts on the cost functions identify the process or activity rather than the commodity. Since the implied commodity prices depend on the commodity bundle consumed, they reflect the household's tastes as well as goods prices and the household's technology.

In production theory an entrepreneur has no inclination to devote homogeneous labor to one activity rather than another except in order to maximize the value of his output. In the household, time spent in various activities is often a direct source of satisfaction or dissatisfaction as well as an input into a production activity. This is a case of joint production, and the household production function approach is not a suitable framework for analyzing joint production. We conclude that the household production function model provides a satisfactory account of the allocation of time only for households which are indifferent among alternative allocations of their time. 


\section{Alternative Approaches}

When commodity prices depend on household tastes, we need an alternative to studying the demand for commodities as functions of commodity prices. One possibility is to regard the demand for commodities as functions of goods prices, the wage rate, nonlabor income, and the household's technology. This provides a suitable framework for analyzing the demand for commodities when the household's technology exhibits joint production or nonconstant returns to scale. It retains the household production function model's emphasis on commodities while dispensing with commodity prices. But this approach is appropriate only when studying variables which are the outputs of production processes. When household activities can more plausibly be interpreted as directly producing a specific type of utility or satisfaction, the appropriate alternative is to analyze the "inputs"- the allocation of goods and time among household activities - as a function of goods prices, the wage rate, and nonlabor income.

\section{A. Commodities as Functions of Goods Prices}

Even with joint production or nonconstant returns, it is possible to estimate the household's technology and construct commodity prices. The commodity prices, however, depend on the commodity bundle consumed as well as on the goods prices and the household's technology. In this case, we believe that it is best to dispense with commodity prices as arguments of the demand function for commodities and to treat the demand for commodities as a function of goods prices, wage rates, and nonlabor income. This has the effect of making the household's technology a parameter of the demand functions, but we believe this is preferable to building tastes into commodity prices. First, it is a conceptual advantage to define prices so that they reflect the constraints facing the household, but not its tastes. This is consistent with the traditional role of prices in demand analysis, where they represent constraints on feasible behavior and are independent of tastes. Second, prices which depend on tastes are not particularly useful analytical constructs. The theorems of traditional demand theory presuppose that the household is a price taker.

Formally, maximizing $U(Z)$ subject to the constraint $C(P, w, Z)=$ $A+w T$ yields demand functions which we denote by $Z=g(P, w, A)$. These demand functions show the household's consumption of commodities as functions of goods prices, the wage rate, and nonlabor income instead of as functions of commodity prices and implicit income. Technical progress - changes in the household's technology - as well as taste change will be reflected by shifts in these demand functions. Because there is no natural correspondence between goods prices and commodity quantities, 
the Slutsky sign and symmetry conditions have no meaning for the demand functions $Z=g(P, w, A)$.

The $Z=g(P, w, A)$ demand functions reflect the influence of both technology and tastes, and, without explicit estimates of the technology, we cannot tell whether variations in consumption are due to variations in tastes or to variations in technology. To argue that all variations in consumption behavior should be attributed to variations in technology because we have a better theory of technology than of tastes is logically unconvincing. Furthermore, although it may be possible to explain consumption behavior in terms of either taste change or technical progress, the welfare implications are quite different.

\section{B. Commodities - Technology versus Tastes}

In the previous section, we suggest that in the presence of joint production or nonconstant returns, the demand for commodities be treated as a function of goods prices rather than commodities prices. In this section, we discuss the case of variables which should not be interpreted as commodities and which are not suitable as dependent variables of demand functions.

A fundamental problem in many applications of the household production function model is the need to assume that household activities being investigated are production processes. If a household activity is a production process, we call the outputs commodities. For example, the commodity "heat" is produced by a furnace and fuel. The relevance of technology for some situations, however, does not imply its relevance for all. Specifically, in some potential applications, the variables being investigated are not "commodities" (the outputs of production processes) but rather utilities (numbers representing preference orderings). These misapplications confound tastes with technology by interpreting specific utility functions as production functions. ${ }^{18}$

Our point is essentially an applied rather than a theoretical one. Consider, for example, the notion of "child quality." One approach to child quality in terms of the household production function model is to assume that market goods and time produce (perhaps jointly) a number of narrowly defined child-related commodities. The vector of these narrowly defined commodities may include variables such as verbal, mathematical, and artistic skills, grades in school, and even the negative

${ }^{18}$ It might be thought that this difficulty could be described in terms of "measurability"; that is, commodities are cardinally measurable while utilities are ordinally measurable. This, however, is not the case. Even the discovery of a unique cardinal measure of utility would not alter our objection to the confounding of tastes and technology in the household production function model. We believe, however, that some thought should be given to the status of ordinal variables as inputs or outputs in production theory, especially when unique indices are not widely accepted. 
of the number of cavities. A second approach, again using the household production function model, is to treat "child quality" as itself a commodity produced by the household's technology. We believe that the aggregation of the narrowly defined child-related commodities into a single index of child quality reflects the preference ordering of the household and not its technology. ${ }^{19}$

In the household production function model as well as in the traditional demand theory approach, the household is maximizing utility rather than output. In applying production theory to the household, the household production function literature has not attempted to draw the line indicating where production processes stop and utility begins. In empirical work, where direct measures of the relevant variables are not available, the two are easily confused.

For example, suppose that the household's utility function is separable, the goods are partitioned into subsets such as food, clothing, and housing, and the utility function is of the form

$$
V(X)=W\left[V^{1}\left(x_{1}\right), \ldots, V^{m}\left(x_{m}\right)\right]
$$

where the $V$ 's are "specific utility functions." This is similar to a household production function model in which no good is used in the production of more than one commodity; it differs from the household production function model only because the "outputs" of the specific utility functions are not measurable. ${ }^{20}$ Hence, in the absence of direct measures of the commodities produced by the household production function, it may be difficult to distinguish between a production function and a specific utility function interpretation of the household's behavior.

Even if we have no observations on the production of commodities by the household, we can still study the allocation of time and goods among household activities. Although Becker, in his seminal article "A Theory

\footnotetext{
${ }^{19}$ Recent papers which discuss the quality of children as an output of a production process include DeTray (1973), Michael (1973), and Willis (1973). For a criticism of this approach similar to ours, see Reid (1973). Lindert (1973) presents an alternative approach which foregoes calculating the price of a child and instead concentrates on actual cost data from budget studies. He argues that the price of a child includes psychic value and is thus not useful for empirical work. See also Gronau (1973).

${ }^{20}$ Muth (1966, p. 700) suggests that the household production function model yields "a utility function which is weakly separable when viewed as a function of commodities [e.g., goods] purchased on the market." Nerlove (1974) quotes this with approval, while Michael and Becker (1973) are more cautious, suggesting that the model implies that the utility function "is separable in the goods and time used to produce a given commodity" (italics are ours). We agree with Muellbauer (1973), who points out that separability is an extra assumption, not a consequence of the basic household production function model. A good like electricity may be used in the production of many commodities without implying joint production or nonconstant returns. The assertion made by Michael and Becker is technically correct, but the implication of their observation is that electricity used for cooking and electricity used for heating must be treated as two distinct goods.
} 
of the Allocation of Time," concentrates on household production functions and the resulting commodities, a study of the underlying activity or input demand functions provides a feasible alternative. ${ }^{21}$

To study the allocation of goods and time within the household, we assume that the household allocates both goods and time among activities. Suppose that there are $l$ activities, and we let $Y_{r}$ denote the vector of goods devoted to activity $r$ and $t_{r}$ denote the household time devoted to activity $r$. We let $(Y, t)$ denote the vector specifying the allocation of goods and household time among activities. In the household production function model there is a vector of commodities associated with each activity; in the example involving cooking and cleaning each activity produced two commodities. The utility function $U(Z)$ enables us to assign a utility to each activity-input vector,

$$
W(Y, t)=U(Z)
$$

where $Z$ is the commodity vector produced by $(Y, t)$. Maximizing this utility function subject to the budget constraint

$$
\sum_{s=1}^{l} \sum_{k=1}^{n} p_{k} y_{s k}+w \sum_{s=1}^{l} t_{s} \leq A+w T
$$

implies a system of demand functions for activity inputs. We denote these input demand functions by

$$
\begin{aligned}
y_{r i} & =F^{r i}(P, w, A) \\
t_{r} & =F^{t r}(P, w, A)
\end{aligned}
$$

or, in vector form, $(Y, t)=F(P, w, A)$.

Even if there are no observable outputs, we can still derive the demand functions for the activity inputs as functions of $P, w$, and $A$ from the utility function $W(Y, t) .^{22}$ The existence of demand functions for the $y_{r i}$ variables, however, does depend on our ability to distinguish the use of good $i$ in activity $r$ from its use in other activities. Similarly, in order to

21 One can study the allocation of time without making use of household production function constructs (see Mincer 1962, 1963). Although his theoretical discussion combines goods prices and wages into a commodity price construct, his empirical work enters these prices separately.

22 Becker's analysis does not distinguish sharply between the household's consumption of commodities and the allocation of goods and time within the household. In part this reflects his assumption that commodities are produced by a fixed-coefficient technology, so that household time devoted to the production of commodity $r$ is proportional to the household's output of commodity $r$. When the technology exhibits fixed coefficients, it is possible to use the input of household time as a proxy for the output of the commodity; but when the technology permits substitution of goods or hired labor for the time of household members, then it is necessary to distinguish between the input of household time and the output of commodities. 
study the allocation of time, it must be possible to divide the day into nonoverlapping activities. If this can be done, then the allocation of time and goods among activities can be analyzed without the household production function apparatus. In any case, the above condition is also necessary for the household production function approach to be relevant. Hence, a study of the allocation of time and goods among activities requires fewer assumptions than does the study of commodities. In particular, it avoids the need to assume that a commodity is actually being produced by a technological process.

\section{Conclusions}

In this paper we have provided a critique of the new theory of household behavior based on household production functions, and, in particular, of its application to problems involving the allocation of time. Where the new theory does not provide a viable model, we have suggested alternative approaches.

The application of the household production function approach requires constant returns to scale and the absence of joint production. If these conditions are not satisfied, commodity prices depend on the household's preferences, and therefore fail to serve the traditional role of prices in consumer theory; that is, they do not code all the relevant information about the constraints faced by the household. Hence, if the household's technology exhibits nonconstant returns to scale or joint production, demand functions based on commodity prices are seriously misleading.

When the production of a commodity involves inputs of the household's time, the production process is likely to exhibit joint production. This is because the household derives utility or disutility from the time it devotes to each activity as well as from the nominal "commodity output" of the activity. Technically, the household time devoted to an activity is both an input and an output, and, if the activity yields other commodity outputs as well, the activity exhibits joint production. When the technology exhibits joint production or nonconstant returns to scale, we suggest that the demand for commodities be analyzed in terms of goods prices rather than commodity prices.

The household production function approach has been applied to cases in which the variable under study may be more appropriately viewed as a utility than as the output of a production process. If commodities are not being produced, it makes no sense to analyze the demand for them; but we can, however, examine the household's allocation of goods and time among activities as a function of goods prices and the wage rate, provided only that these allocations are themselves observable. 


\section{References}

Becker, Gary S. "An Economic Analysis of Fertility." In Demographic Change in Developed Countries. Universities-National Bureau Conference Series 11. Princeton, N.J.: Princeton Univ. Press, 1960.

- "A Theory of the Allocation of Time." Econ. J. 75, no. 299 (September 1965): 493-517.

DeTray, Dennis N. "Child Quality and the Demand for Children." J.P.E. 81, no. 2, pt. 2 (March 1973): 70-90.

Diewert, W. E. "Choice on Labour Markets and the Theory of the Allocation of Time." Department of Manpower and Immigration, Ottawa, 1971.

- "Applications of Duality Theory." Discussion Paper no. 89, Univ. British Columbia, 1972.

Gronau, Reuben. "The Effect of Children on the Housewife's Value of Time." J.P.E. 81, no. 2, pt. 2 (March 1973): 168-99.

Hall, Robert E. "The Specification of Technology with Several Kinds of Output." J.P.E. 81, no. 4 (July 1973): 878-92.

Lancaster, Kelvin J. "A New Approach to Consumer Theory." J.P.E. 74, no. 2 (April 1966): 132-57. (a)

- "Change and Innovation in the Technology of Consumption." A.E.R. 56, no. 2 (May 1966): 14-23. (b)

- Consumer Demand: A New Approach. New York: Columbia Univ. Press, 1971.

Lindert, Peter H. "The Relative Cost of American Children." Economic History Discussion Paper, Eh73-18, Univ. Wisconsin, March 1973.

Michael, Robert T. "Education and the Derived Demand for Children." J.P.E. 81, no. 2, pt. 2 (March 1973): 128-64.

Michael, Robert T., and Becker, Gary S. "On the New Theory of Consumer Behavior." Swedish J. Econ. 75 (1973): 378-96.

Mincer, Jacob. "Labor Force Participation of Married Women." In Aspects of Labor Economics, edited by H. Gregg Lewis. Universities-National Bureau Conference Series 14. Princeton, N.J.: Princeton Univ. Press, 1962.

- "Market Prices, Opportunity Costs, and Income Effects." In Measurement in Economics: Studies in Mathematical Economics and Econometrics in Memory of Yehuda Grunfeld, edited by C. Christ et al. Stanford, Calif.: Stanford Univ. Press, 1963.

Muellbauer, John. "Household Production Theory, Quality and the 'Hedonic Technique.", A.E.R. (in press).

Muth, Richard F. "Household Production and Consumer Demand Functions." Econometrica 34, no. 3 (July 1966): 699-708.

Nerlove, Marc. "Household and Economy: Toward a New Theory of Population and Economic Growth." J.P.E. 82, no. 2, pt. 2 (March/April 1974) : 200-218.

Reid, Margaret G. "Comment." J.P.E. 81, no. 2, pt. 2 (March/April 1973): 165-67.

Willis, Robert J. "A New Approach to the Economic Theory of Fertility Behavior." J.P.E. 81, no. 2, pt. 2 (March/April 1973): 14-65. 
